\title{
The Netherlands
}

\author{
David Banta \\ Professor Emeritus, University of Maastricht
}

\author{
Wija J. Oortwijn \\ ECORYS Nederland BV
}

Objective: The aim of this report was to describe the history of health technology assessment $(\mathrm{HTA})$ in the Netherlands.

Methods: This article is a descriptive review from two people who have been very much involved in the events described and is based on review of relevant policy documents and Web sites.

Results: HTA has been progressively developed in the Netherlands since (at least) the early 1980s. Beginning in 1985, there were progressive attempts to expand and institutionalized HTA in the Netherlands healthcare system. These attempts were generally successful, but did not result in a national agency for HTA. An important development in HTA in the Netherlands was a special fund (Ontwikkelingsgeneeskunde) designed to support prospective HTAs with the main purpose of affecting insurance coverage decisions. The administration of this fund moved progressively to broaden the subjects chosen for analysis to include such subjects as chronic illness and disability. A more-or-less hidden conflict developed in the question of the leadership and orientation of this fund, with the result that it was largely moved to a more research-oriented and less policy-oriented site.

Conclusions: The situation today is that HTA is visible and is used by the government in policy decisions, especially in the areas of prevention and screening. In addition, HTA is influential in insurance coverage decision making, especially in the field of pharmaceuticals. The principles of HTA and evidence-based medicine are generally familiar to physicians and other clinicians, however, the influence of HTA on clinical and administrative decisions is less than in some other countries.

Keywords: Health technology assessment, History, The Netherlands, Decision making, Health planning

The healthcare system of the Netherlands is made up of private institutions and individuals to ensure essentially universal access to high-quality healthcare services. Hospitals are largely private, general practitioners are private, and specialists work either in hospitals on salary or in private practice, or both. However, the system is highly regulated to ensure that high-quality care is provided with reasonable efficiency to the entire population (4). Principles of equality, equity, and solidarity are highly regarded. The Ministry of Health, Welfare and Sport (referred to hereafter as Ministry of Health) has the responsibility for ensuring that the system provides necessary care to all.

The system has been in almost continual change for the past decades. In 2006, the health insurance system changed from a public/private mix to a private health insurance with social conditions that is obligatory for every inhabitant of the Netherlands (the so-called Health Insurance Act). The key elements of this new act are (i) a new standard insurance for all, (ii) citizens are allowed to change their insurance company every year, (iii) insurance companies compete with each other on price and the quality of care, (iv) customers and insurers stimulate suppliers to provide better quality, (v) and compensation for people with low incomes (16)

Presently, the system is being reformed to bring more market forces into health care, with financial incentives designed to make the system more efficient. In fact, what is under way is a vast experiment.

Regulations include (i) regulation of drugs for efficacy, safety and cost-effectiveness; (ii) increasing regulation of medical devices; (iii) planning and regulation of health 
services (with strong controls over hospital-based technology); (iv) budgets and payment controls aimed at controlling costs, with a strong approach to defining a benefit package available to all; (v) growing formal attention to quality of care; and (vi) determining which forms of care are covered by healthcare insurance.

\section{DEVELOPMENT OF HEALTH TECHNOLOGY ASSESSMENT (HTA)}

HTA has been part of Dutch policy making for decades, mainly through the work of the Health Council (Gezondheidsraad), which advises the government on the state of science regarding issues of health care, public health, and environmental protection. In the early 1980s, however, the Health Insurance Council (now the Health Care Insurance Board, College voor zorgverzekeringen, CVZ) and the Ministry of Health became concerned about the rapid developments in health technology and their impact on health care and society, especially in terms of cost (4).

Around 1982, the Health Insurance Council was under increasing pressure from patients who demanded that the costs of heart and liver transplants performed abroad should be reimbursed by sick funds. Because of the ensuing debate, the Health Insurance Council developed a report in 1985, Limits to the Expansion of the Benefit Package (19), stating that, in the future, all new major health technologies were to be assessed for their efficacy and cost-effectiveness and would be admitted to the benefit package according to their priority.

In 1985, three major evaluations, of heart transplantation, liver transplantation, and in vitro fertilization, were funded by the Health Insurance Council and carried out in academic centers (4). In the meantime, those procedures were only provided in the context of the evaluations. After completion of the studies in 1988 and 1989, all three became part of the benefit package, but with some delays in decision making.

During the 1980s and the 1990s, a series of policyoriented reports were carried out that either focused on HTA or included HTA as part of future policy in the Netherlands. In summary, all of these reports recommended a strong program of HTA as part of Dutch health care $(4 ; 9 ; 10 ; 15)$.

An especially visible report was from the so-called Dunning Committee, chaired by Professor Dunning, a prominent academic cardiologist (8). The Committee recommended in 1991 that four screens should be used to define a basic benefit package available to all. First, is the care necessary, meaning is it necessary to ensure normal function or to protect life? Second, has the intervention proven to be effective in controlled clinical trials? Third, is the care efficient, meaning has it been shown to be cost-effective by formal analysis? And fourth, is it possible to leave the care up to individual responsibility? This report was not totally imple- mented, but it defined the terms of the debate and made HTA essentially an essential part of government health policy.

Since 2006, the main role of the CVZ is managing the benefit package of health care. An important task of the CVZ is to give advice, both solicited and unsolicited, to the Ministry of Health concerning which care is reimbursed for what patients, and what the content of insured health care should be. By assessing health interventions, the CVZ assesses whether the intervention is defined as health care as described in the laws, and whether it should be included in or excluded from the benefit package. In assessing health interventions, the CVZ uses four principles: (i) Necessity: Does the disease or care needed justify, given the context in society, a claim for solidarity? (ii) Effectiveness: Does the intervention or care provision deliver what is expected of it? (iii) Cost-effectiveness: Is the relationship between costs and benefits acceptable? and (iv) Feasibility: Is it feasible and sustainable, now and in the future, to include the intervention or care provision in the benefit package? (12).

\section{CREATING A FUND FOR HTA}

In 1988, in the midst of the flurry of policy documents, the Ministries of Health and of Education and Science, as well as the Health Insurance Council, acted together to create a national fund for investigative medicine (Commissie Ontwikkelingsgeneeskunde), with a budget of approximately US\$18 million a year (4). The fund was essentially used to fund assessments of mostly new health technologies, carried out in academic medical centers. The fund led to all eight medical faculties developing programs of HTA. The assessments were, at that time, prospective research, usually controlled clinical trials with cost data collected simultaneously. The main outcome of the resulting assessment was advice from the Health Insurance Council to the Minister of Health on whether a technology should be covered by insurance as a routine or not.

A debate grew up around this fund, especially the fact that it was administered by the Health Insurance Council. Many were concerned that the Council would be mainly oriented to containing healthcare costs, and not necessarily to improving quality of care or promoting useful innovation. In part, those who took this line were academics or part of the research establishment who may have wished to have more control over the funds. Also, the administrators of the fund were moving to devote more resources to high-priority problems such as chronic diseases, mental health, and disabilities, and to devote fewer resources to assessments of new hospitalbased technology. This change in the program was surely an important part of the growing pressures to move the program to a more academic and research-oriented environment. The end result was to move the program to the Netherlands Organization for Health Research and Development (ZonMw). In 2000, the Health Care Efficiency program-Programma 
DoelmatigheidsOnderzoek (with an annual budget of 12.2 million Euro) — was implemented and commissioned by the Dutch Minister of Health, Welfare, and Sport. In 2001, the first grants for this program were allocated (17).

\section{THE DUTCH SOCIETY FOR HEALTH TECHNOLOGY ASSESSMENT}

The Dutch Society for HTA (Nederlandse Verengiging voor Technology Assessment in de Gezondheidszorg-NVTAG) was formed in 1995. The purpose was to provide a forum mainly for the younger workers in HTA who would usually have difficulty in gaining support to participate in the international society meetings. Today, the Society has approximately 150 members. It organizes at least one conference each year, at which a prize for the best article of an excellent young HTA researcher is presented. The Web site for the Society is www.nvtag.nl.

\section{THE NEED FOR AN HTA AGENCY}

The need for a national HTA agency was debated and under consideration for several decades. A report supported by the Steering Committee for Future Health Scenarios proposed a national HTA agency and system in 1987 (3). A follow-up report by some of the same authors examined this idea further in 1995 (2). However, for reasons that never became clear, there were no serious moves in that direction. Part of the reason was surely that the Dutch orientation to government is that it should function largely to make private initiatives possible.

The result has been that HTA has never been as strong in the Netherlands as it could have been. After the move of the investigative medicine fund to $\mathrm{ZonMw}$, the orientation became less policy oriented and more oriented to scientific and clinical issues. HTA seems less important now than it did 10 years ago, with some exceptions.

\section{COVERAGE POLICY FOR PHARMACEUTICALS}

Coverage of pharmaceuticals is similar to general coverage in the Netherlands, but is further developed and based on the Dunning Committee principles. The process requires formal economic analysis, should the pharmaceutical industry want to settle a price outside the existing reference pricing system.

In 1997, the Minister of Health asked the Health Insurance Council to formulate guidelines for pharmacoeconomic evaluation. The resulting 19 guidelines (6) are based on Canadian pharmacoeconomic guidelines (5) and focus on target groups, the perspective of study, indications, methods of analysis, definition of costs, methods for measuring costs, determination and valuation of quality of life, the reference treatment to be used, outcome measures, reliability, validity, and results. According to these guidelines, a cost-effectiveness analysis should be performed on those pharmaceuticals for which the manufacturer claims added value compared with existing treatment options. The responsibility of performing pharmacoeconomic research lies with the manufacturer. This means that a manufacturer needs to demonstrate information on cost-effectiveness of the new pharmaceutical before claiming additional value of this new pharmaceutical compared to existing interventions. The new system was implemented on a voluntary basis, before it came into full use in $2005(7 ; 18 ; 20)$. Hence, economic evaluations play a role in decision making on these new and innovative drugs. However, for "me too" drugs, the reference pricing system, guaranteeing a set upper price for the majority of drugs, does not include any incentive to make the pharmaceutical market more efficient. Therefore, Dutch government's attempts to control pharmaceutical spending have been successful only to a limited extent.

\section{PREVENTION IN THE NETHERLANDS}

Prevention policy in the Netherlands is especially interesting. The Dutch government has given a strong endorsement to prevention (1). Primarily, the Ministry of Health is responsible for policy regarding the following aspects of prevention: (i) prevention of diseases by immunization, screening, and medication; (ii) health protection by developing and enforcing laws and legislation (for example, on smoking in public spaces); and (iii) health promotion by offering general information and tailor-made advice and the creation of physical surroundings that stimulate healthy behavior (14).

The general policy of the government is that prevention programs should meet high standards of effectiveness and efficiency as well as ethical, legal, and social acceptability. Health problems are chosen as priorities on the basis of criteria such as the burden of disease and the availability of effective and acceptable preventive interventions. Funding is available to examine the questions of the burden of disease and the effectiveness of preventive interventions addressed to them.

\section{SCREENING IN THE NETHERLANDS}

Screening is part of the Netherlands policy for prevention. In 1986, the Dutch Ministry of Health funded a study of the effects of breast cancer screening on mortality and morbidity if such a program were implemented in the Netherlands (11). Data from pilot projects in two cities were used to develop a national model on breast cancer screening, including a costeffectiveness analysis. The results were positive in terms of both health outcomes and cost-effectiveness. This was the first cost-effectiveness analysis done in the Netherlands for the purposes of policy making. 
At the same time, the government and the parliament were concerned that screening could be expensive and could also result in physical or mental harm to those taking part in a program. Therefore, the Parliament passed a law on population screening in 1996 (13). The law states that all proposals for population screening must seek approval from the Minister of Health before they are launched. The law further provides that all proposals for population screening should be presented to a special committee based at the Health Council. The Committee advises the Minister, and also carries out other tasks, such as monitoring on-going screening programs.

The problem with screening is that it is in fact difficult to control. Much screening is done as opportunistic screening. A patient visits a physician and a diagnostic test is used to screen that person and the diagnostic test is paid for. Several cases, including screening for prostate cancer and ultrasound screening in pregnancy are done frequently, despite lack of proven efficacy and reports advising against such practices.

\section{DISCUSSION}

HTA has now been implemented in a widespread manner in the Netherlands for approximately 20 years. HTA is quite visible, but mainly as cost-effectiveness studies. Coverage policy, especially concerning pharmaceuticals, relies greatly on such studies. These studies are well-accepted by policy makers. Clinicians, especially academic physicians seem more involved in evidence-based medicine, meaning that they use mainly information on efficacy, and in an unsystematic way. The general public has been little involved in these developments.

In the opinion of the authors, the struggle for control of the HTA programs between policy makers, especially those involved with health insurance, and clinical investigators has not been of benefit to the field. The desirable course would have been to develop a national HTA agency, as most other countries with effective HTA activities have done. Today, although HTA is a visible activity, and most physicians would state that evidence-based medicine is an important concept that should guide health services, HTA activities have a limited impact on clinical practice.

On the other hand, the Dutch government has become very involved in prevention and screening and has made HTA an important part of these activities. As a result, the Netherlands has one of the best prevention programs in the world.

\section{CONTACT INFORMATION}

David Banta, MD MPH (HD.Banta@orange.fr), 9 route de Bragelogne, 10210 Villiers-le-Bois, France
Wija J. Oortwijn, PhD (wija.oortwijn@ecorys.com), Principal Consultant, Department of Macro \& Sector Policies, ECORYS Nederland BV, Watermanweg 44, 3067 GG, Rotterdam, The Netherlands

\section{REFERENCES}

1. Banta HD, Oortwijn W. Health technology assessment and screening in the Netherlands: Case studies of mammography in breast cancer, PSA screening in prostate cancer, and ultrasound in normal pregnancy. Int J Technol Assess Health Care. 2001;17:369-377.

2. Banta HD, Oortwijn WJ, Van Beekum WT. The organization of health care technology assessment in the Netherlands. The Hague: The Rathenau Institute; 1995.

3. Banta D, Gelijns A, eds. Anticipating and assessing health care technology. vol. 1. General considerations and policy conclusions. Dordrecht: Martinus Nijhoff Publishers; 1987.

4. Bos M. Health care technology in the Netherlands. In: Health care technology and its assessment in eight countries. Washington, DC: US Government Printing Office; 1995:171208.

5. Canadian Coordinating Office for Health Technology Assessment. Guide for economic evaluation of pharmaceuticals. 2nd ed. Ottawa: Canadian Coordinating Office for Health Technology Assessment; 1997

6. College voor zorgverzekeringen (Health Care Insurance Board). Richtlijnen voor farmacoeconomische onderzoek [Dutch guidelines for pharmacoeconomic research]. Amstelveen: College voor zorgverzekeringen; 1999.

7. De Wolf P, Brouwer WB, Rutten FF. Regulating the Dutch pharmaceutical market: Improving efficiency or controlling costs? Int J Health Plann Manage. 2005;20:351-374.

8. Dunning A. Committee on choices in health care (Kiezen en Delen). Rijswijk: Ministry of Health; 1991.

9. Health Council. Medical practice at the crossroads. The Hague: Health Council; 1996.

10. Health Insurance Council. Assessment of the benefits package regarding pharmaceuticals. Publication 680. Amstelveen: Ziekenfondsraad; 1997.

11. Institute for Medical Technology Assessment (iMTA). The costs and effects of mass screening for breast cancer. Rotterdam: Erasmus University Rotterdam; 1987.

12. Mastenbroek CG, Van Der Meer FM, Zwaap J, Fikken F, Polman MPH. Pakketbeheer in de praktijk. Diemen: College voor zorgverzekeringen; 2006.

13. Ministry of Health. Law on population screening. Rijswijk: Ministry of Health; 1996.

14. Ministry of Health. Prevention. http://www.minvws.nl/en/ themes/prevention/default.asp (accessed September 2008).

15. Ministry of Health. Progress report on medical technology assessment and cost-effectiveness of care. Rijswijk: Ministry of Health, Welfare and Sport; 1997.

16. Ministry of Health. The new care system in the Netherlands (in three languages). http://www.minvws.nl/en/folders/z/ 2006/the-new-health-insurance-system-in-three-languages.asp (accessed September 2008). 
17. Oortwijn W, Hanney SH, Ligtvoet A, et al. Assessing the impact of health technology assessment in the Netherlands. Int J Technol Assess Health Care. 2008;4:259269.

18. Oostenbrink JB, Bouwmans CAM, Koopmanschap MA, Rutten FFH. Handleiding voor kostenonderzoek: Methoden en richtlijnprijzen voor economische evaluatie in de gezondheidszorg [Manual for costing research: Methods and reference prices for economic evaluation in healthcare]. Amstelveen: College voor zorgverzekeringen; 2004.

19. Rigter H. Assessment of health care technology in the Netherlands. In: Banta D, Luce B, eds. Health care technology and its assessment. Oxford: Oxford University Press; 1993:213-222.

20. Toenders WGM. Breedte geneesmiddelenpakket [Breadth of the benefits package regarding pharmaceuticals]. Amstelveen: College voor zorgverzekeringen; 2001. 